\title{
Review
}

\section{Possible Effects of Internet Use on Cognitive Development in Adolescence}

\author{
Kathryn L. Mills \\ Department of Psychology, University of Oregon, Eugene, OR 97403, USA; E-Mail: klmills@uoregon.edu
}

Submitted: 24 November 2015 | Accepted: 7 March 2016 | Published: 16 June 2016

\begin{abstract}
The rise of digital media use and the ability to be in almost constant connection to the Internet has raised a number of concerns about how Internet use could impact cognitive abilities. In particular, parents and policy makers are concerned with how being 'constantly online' might disrupt social and cognitive development. This review integrates the latest empirical evidence on Internet use with relevant experimental studies to discuss how online behaviors, and the structure of the online environment, might affect the cognitive development of adolescents. Popular concerns are discussed in light of the reviewed evidence, and remaining gaps in knowledge are highlighted.
\end{abstract}

\section{Keywords}

digital media; multitasking; online; social cognition; social media; social networking

\section{Issue}

This review is part of the issue "Adolescents in the Digital Age: Effects on Health and Development", edited by Dan Romer (University of Pennsylvania, USA).

(C) 2016 by the author; licensee Cogitatio (Lisbon, Portugal). This article is licensed under a Creative Commons Attribution 4.0 International License (CC BY).

\section{Introduction}

How does Internet use affect the cognitive development of adolescents? Parents and policy makers have increasingly voiced their concerns with the effects of Internet use on the developing generation of adolescents (George \& Odgers, 2015). As noted in recent reviews (George \& Odgers, 2015; Mills, 2014), there is still a lack of experimental studies examining the impact of Internet use on cognitive development. The current review focuses on the few studies that have examined the possible effects of Internet use on cognitive processes in adolescents and emerging adults, including social cognitive processes.

The question of how Internet use affects cognition is not straightforward enough to be answered by one or even a series of experiments. Internet use can be considered an environmental exposure variable, similar to musical training or malnutrition. However, unlike musical training or malnutrition, Internet use is an environmental factor that almost the entirety of industrialized nations has been exposed to in recent years. This makes it almost impossible to conduct an experiment comparing groups with and without exposure to the Internet. Indeed, one of the main concerns about Internet use is not just how using the Internet can impact cognitive processes such as memory or social understanding, but how having constant access to the Internet might impact these cognitive processes.

To properly address the question of how Internet use could affect the cognitive development of adolescents, empirical studies can either utilize measures of actual Internet use or incorporate the distinct features of Internet use into cleverly designed laboratory experiments. These features can be defined as online behaviors, which include (but are not limited to) information gathering and communication. These features can also be conceptualized as structures present in the online environment, which include access to vast stores of information, communication through text, and virtual peer evaluation. This review will integrate empirical evidence from experimental studies including online behaviors or online structures when relevant studies incorporating measures of actual Internet use are lacking.

Investigating the effects of Internet use on cognition in adolescents is warranted given the continued 
development of cognitive processes into the twenties (Luna, Marek, Larsen, Tervo-Clemmens, \& Chahal, 2015). These cognitive processes include, but are not limited to, working memory capacity, attentional control, and social cognition. Specific concerns about how the Internet might impact adolescent cognitive development include how having near-constant access to information might disrupt memory abilities or the utilization of effortful thinking (Näsi \& Koivusilta, 2012), or how the ability to multitask between several online/offline activities could shorten attention spans. While these concerns about altered cognitive abilities are often couched within the idea that 'Internet use could be rewiring developing brains', the current review focuses specifically on cognitive processes rather than neural correlates or neural development.

\section{How the Internet Is Being Used Today}

To understand how Internet use might affect adolescent cognitive development, it is first necessary to describe just how adolescents are using the Internet. In late 2014 and early 2015, the Pew Research Center surveyed the Internet use of 1,060 American adolescents aged 13 to 17 years (Lenhart, 2015). Of the sample, $92 \%$ reported using the Internet daily, with $24 \%$ of the sample going online 'almost constantly.' In this survey, teens with mobile devices were more likely to access the Internet frequently than teens without mobile devices, with $94 \%$ of teens that access the Internet from mobile devices reporting going online at least daily versus $68 \%$ of teens who do not access the Internet from mobile devices (Lenhart, 2015). This most recent national survey of Internet use suggests that teenagers are using the Internet frequently, but are not limited to accessing the Internet from a stationary device.

Adolescents report engaging in a variety of online activities, but many aspects of Internet use, from social networking sites to multiplayer video games, involve communicating with peers. In an interview study of 128 American 13 to 14 year olds, 85\% reported using information technologies for communication purposes (Fitton, Ahmedani, Harold, \& Shifflet, 2013); a study of 10,930 adolescents spanning 6 European countries found that approximately $70 \%$ of adolescents aged 14 to 18 years reported using social networking sites daily (Tsitsika et al., 2014). The primary reason why adolescents use social networking sites is to connect with individuals known offline (Reich, Subrahmanyam, \& Espinoza, 2012).

An important but rarely addressed consideration is the multitasking nature of most Internet use. The 2015 Common Sense Census report acknowledges that digital media use (which includes Internet use) can occur simultaneously with other activities such as physical activity, household chores, or commuting (Common Sense Media, 2015). Thus, using the Internet does not necessarily displace engagement in other activities. To further complicate matters, socializing online can occur simultaneously with socializing offline, as social media use is also an activity that can be shared among those friends present in the same offline setting (similar to video game play).

Finally, the 2014-2015 Pew Research Center Teen Relationships Survey suggests that Internet use might actually complement, rather than displace time spent communicating face-to-face, as more teens reported spending time with their closest friend at school (83\%) or at someone's house (58\%) than reported spending time with their closest friend online (55\%) (Lenhart, Smith, Anderson, Duggan, \& Perrin, 2015). And while many adolescents who play video games do so with other online 'gamers' (75\%), more tend to play video games with their friends in person (89\%) (Lenhart et al., 2015).

\section{This Is Not a Review of Disordered Internet Use}

Many studies investigating Internet use and cognitive processes in adolescents have focused specifically on a subgroup of adolescents with disordered Internet use (also referred to as Problematic or Pathological Internet Use). These studies often make headlines, which can skew the public's perception into thinking that Internet use is harming adolescents. However, as by design these studies investigate a sample of the population selected because they are experiencing difficulties. Indeed, while large population surveys have found high rates of Internet use among American teenagers, the prevalence of disordered Internet use remains low. One recent large population survey spanning 11 European countries looked at the prevalence of Pathological Internet Use (PIU) in a sample of 11,956 adolescents and found that only $4.4 \%$ of adolescents met criteria for PIU (Durkee et al., 2012). This suggests that many of the studies investigating PIU do not apply to the majority of adolescents, a finding further corroborated in a longitudinal study of 1,444 adolescents that found that PIU wavered between $4.4 \%$ and $3.1 \%$ across three time points, with only 3 participants continually showing persistent PIU (Strittmatter et al., 2015). Another longitudinal study found a significant decrease in PIU between ages 14 to 16 years (Barrense-Dias, Berchtold, Akre, \& Surís, 2015). It appears that selfregulating capacities are crucial for predicting which adolescents will develop PIU. In a longitudinal study of 801 Spanish adolescents aged 13 to 18 years, the ability to regulate one's Internet use at baseline predicted the amount of negative consequences experienced from Internet use six months later (Gámez-Guadix, Calvete, Orue, \& Las Hayas, 2015).

\section{Methods}

Relevant studies were first identified through a litera- 
ture search using the PubMED database to identify all available peer-reviewed studies that contained the following three keywords: 'adolescence' and 'internet' and 'cognition'. Specifically, the search was the following string: ('cognition' [MeSH Terms] OR 'cognition' [All Fields]) AND ('internet' [MeSH Terms] OR 'internet' [All Fields]) AND ('adolescent' [MeSH Terms] OR 'adolescent' [All Fields] OR 'adolescence' [All Fields]). Each of the 249 articles that met these criteria at the time of this search were then examined and categorized into the following five categories: Relevant, Application, Clinical, Review, Cyberbullying, or Irrelevant (see tables at osf.io/pq25d). An article was classified as Relevant if it included cognitive measures in relation to online behaviors and/or online structures (as described in the Introduction) in a group of adolescents or emerging adults. No studies met these criteria. In light of this, a more dynamic search procedure was used, and further studies were identified by reviewing citations to, and citations within, relevant reviews and empirical articles related to Internet use and cognition.

\section{Results}

Several studies were identified that utilized experimental paradigms to explore how structures present in the online environment, such as access to information and communication through text, affected the cognitive processes of participants. There were a few studies of cognitive processes that included measures of real-life online behaviors, such as social networking site use. While some studies included adolescent samples, others investigated effects in college-aged samples, or 'emerging adults'. The studies are subdivided based on the cognitive process investigated. The demographic characteristics of these studies are summarized in Table 1.

\subsection{Memory}

One of the first studies to examine the possible effects of ubiquitous Internet availability on cognitive processes was conducted in 2011 (Sparrow, Liu, \& Wegner, 2011). This study experimentally tested a common concern about how Internet use might affect memory-specifically how having access to information stored in an external source could render individuals less likely to store information in their own memory. Drawing from the theory of transactive memory, where the information known by a group is treated as a memory bank from which individual members can draw (Wegner, 1987), Sparrow et al. (2011) examined how the expectation of having access to information at a later time affected the memory of undergraduate students. They found that when students expected to have future access to information, they were less likely to remember specific information but more likely to remember where to find the specific in- formation (Sparrow et al., 2011). This result would suggest that near-constant access to the Internet could influence the kind of information an individual chooses to remember. This kind of cognitive change could be considered an adaptation to the present environment, as trying to remember many pieces of specific pieces of information is less efficient than remembering how to access these pieces of information when access is easily obtainable.

Given the high levels of information trafficked through the Internet, there have been concerns that exposure to inaccurate information through social media could encourage false memory formation. This hypothesis was tested in a group of undergraduate students who were exposed to false information through a pseudo-Twitter feed compared to a non-social media (but still web-based) source of information (Fenn, Griffin, Uitvlugt, \& Ravizza, 2014). When later probed about how confident they were about specific statements, the group exposed to false information through the pseudo-twitter platform expressed less confidence in the false information presented than the group exposed to the same information in the non-social media platform (Fenn et al., 2014). These results suggest that individuals familiar with social media platforms take into account the reliability of information presented through them.

Finally, it appears that having access to the Internet affects how confident an individual is about her or his own knowledge. One study of undergraduate students found that having access to the Internet decreased an individual's confidence in knowing the answer to a question (Ferguson, McLean, \& Risko, 2015). However, another suite of experiments performed on a group of adults (assessed through Amazon's Mechanical Turk) found that searching for information on the Internet increased an individual's confidence in her or his own stored knowledge (Fisher, Goddu, \& Keil, 2015). Taken together, these studies suggest that having nearconstant access to the Internet could affect how we process and store information. However, as these studies were conducted on college-aged and adult populations, it is unclear if these effects would be present in a sample of adolescents.

\subsection{Analytical Thinking}

Another common concern about Internet use is that it can lead to shallower thinking. One hypothesis underlying this concern is that having instant access to seemingly limitless information takes away the need to engage in more cognitively effortful processes. However, devising an experiment that can gauge how environmental factors impact the depth of one's thinking is no easy challenge. One recent study was able to do so by investigating how both information and cognitive strategy propagated through different kinds of networks 
Table 1. Information for the studies included in this review.

\begin{tabular}{|c|c|c|c|c|c|c|c|}
\hline Authors & Year & Design & $\begin{array}{l}\text { Sample } \\
\text { source }\end{array}$ & Sample size & Age range & $\begin{array}{l}\text { Developmental } \\
\text { comparison }\end{array}$ & Genders \\
\hline Sparrow, Liu, \& Wegner & 2011 & Cross-sectional & USA & $\begin{array}{l}\text { Ex1: 46; Ex2: 60; Ex3: } \\
\text { 28; Ex4: 34; }\end{array}$ & $\begin{array}{l}\text { Undergraduate } \\
\text { students }\end{array}$ & No & Both \\
\hline $\begin{array}{l}\text { Fenn, Griffin, Uitvlugt, } \\
\text { \& Ravizza }\end{array}$ & 2014 & Cross-sectional & USA & 179 & $\begin{array}{l}\text { Undergraduate } \\
\text { students. Mean } \\
\text { age: } 19 \text { years }\end{array}$ & No & Both \\
\hline $\begin{array}{l}\text { Ferguson, McLean, \& } \\
\text { Risko }\end{array}$ & 2015 & Cross-sectional & Canada & $\begin{array}{l}\text { Ex1: 38; Ex2a: 33; Ex2b: } \\
\text { 35; }\end{array}$ & $\begin{array}{l}\text { Undergraduate } \\
\text { students }\end{array}$ & No & $\begin{array}{l}\text { Not } \\
\text { provided }\end{array}$ \\
\hline Fisher, Goddu, \& Keil & 2015 & Cross-sectional & $\begin{array}{l}\text { Interne } \\
t\end{array}$ & $\begin{array}{l}\text { Ex1a: 197; Ex1b: 142; } \\
\text { Ex1b: 195; Ex2a: 192; } \\
\text { Ex2b: 187; Ex3: 280; } \\
\text { Ex4a: 148; Ex4b: 145; } \\
\text { Ex4c: } 131\end{array}$ & $\begin{array}{l}\text { Adults. Mean } \\
\text { age: } \sim 31 \text { years }\end{array}$ & No & $\begin{array}{l}\text { Not } \\
\text { provided }\end{array}$ \\
\hline $\begin{array}{l}\text { Rahwan, Krasnoshtan, } \\
\text { Shariff, \& Bonnefon }\end{array}$ & 2014 & Cross-sectional & USA & 100 & $\begin{array}{l}\text { University } \\
\text { students. 18-26 } \\
\text { years }\end{array}$ & No & $\begin{array}{l}\text { Not } \\
\text { provided }\end{array}$ \\
\hline Ophir, Nass, \& Wagner & 2009 & Cross-sectional & USA & $\begin{array}{l}\text { Ex1: 41; Ex2: 30; Ex3: } \\
30\end{array}$ & $\begin{array}{l}\text { University } \\
\text { students }\end{array}$ & No & $\begin{array}{l}\text { Not } \\
\text { provided }\end{array}$ \\
\hline Alzahabi \& Becker & 2013 & Cross-sectional & USA & Ex1: 92; Ex2: 58 & $\begin{array}{l}\text { Undergraduate } \\
\text { students. Mean } \\
\text { age: } 19 \text { years }\end{array}$ & No & Both \\
\hline $\begin{array}{l}\text { Mills, Dumontheil, } \\
\text { Speekenbrink, \& } \\
\text { Blakemore }\end{array}$ & 2015 & Cross-sectional & UK & 33 & $\begin{array}{l}\text { Adolescents. } \\
11-17 \text { years }\end{array}$ & $\begin{array}{l}\text { Adults: } n=28, \\
22-30 \text { years }\end{array}$ & Females \\
\hline $\begin{array}{l}\text { Sherman, Michikyan, \& } \\
\text { Greenfeld }\end{array}$ & 2013 & Cross-sectional & USA & 29 pairs & $\begin{array}{l}\text { University } \\
\text { students. 18-21 } \\
\text { years }\end{array}$ & No & Females \\
\hline $\begin{array}{l}\text { Teppers, Luyckx, } \\
\text { Klimstra, \& Goossens }\end{array}$ & 2014 & Longitudinal & Belgium & 256 & $\begin{array}{l}\text { Adolescents. } \\
14-19 \text { years }\end{array}$ & No & Both \\
\hline $\begin{array}{l}\text { Tsitsika, Tzavela, } \\
\text { Janikian, Ólafsson, } \\
\text { lordache, } \\
\text { Schoenmakers, Tzavara, } \\
\text { \& Richardson }\end{array}$ & 2014 & Cross-sectional & Europe & 10930 & $\begin{array}{l}\text { Adolescents. } \\
\text { 14-17 years }\end{array}$ & $\begin{array}{l}\text { Younger vs. } \\
\text { older } \\
\text { adolescents }\end{array}$ & Both \\
\hline Yang \& Brown & 2013 & Cross-sectional & USA & 193 & $\begin{array}{l}\text { Undergraduate } \\
\text { students. 17-26 } \\
\text { years }\end{array}$ & No & Both \\
\hline $\begin{array}{l}\text { Somerville, Jones, } \\
\text { Ruberry, Dyke, Glover, } \\
\text { \& Casey }\end{array}$ & 2013 & Cross-sectional & USA & 30 & $\begin{array}{l}\text { Adolescents. } \\
\text { 13-17 years }\end{array}$ & $\begin{array}{l}\text { Children: } n=20 \text {, } \\
8-12 \text { years. } \\
\text { Young adults: } \\
n=19,18-22 \\
\text { years }\end{array}$ & Both \\
\hline $\begin{array}{l}\text { Wolf, Bazargani, Kilford, } \\
\text { Dumontheil, \& } \\
\text { Blakemore }\end{array}$ & 2015 & Cross-sectional & UK & 44 & $\begin{array}{l}\text { Younger } \\
\text { adolescents: } \\
\text { 10-14 years. } \\
\text { Older } \\
\text { adolescents: } \\
\text { 15-18 years. }\end{array}$ & $\begin{array}{l}\text { Adults: } n=20 \\
22-35 \text { years }\end{array}$ & Females \\
\hline $\begin{array}{l}\text { Silk, Stroud, Siegle, } \\
\text { Dahl, Lee, \& Nelson }\end{array}$ & 2012 & Cross-sectional & USA & 60 & $\begin{array}{l}\text { Pre- } \\
\text { adolescents } \\
\text { and } \\
\text { adolescents. } \\
\text { 9-17 years }\end{array}$ & No & Both \\
\hline
\end{tabular}

(Rahwan, Krasnoshtan, Shariff, \& Bonnefon, 2014). In this study, when undergraduate students had access to the answers provided by others in highly-connected networks, they were more likely to correctly answer a question that required analytical reasoning, but were less likely to utilize analytic reasoning in later situations that required this cognitive strategy (Rahwan et al., 2014). These findings indicate that that individuals who are part of a highly connected network (like the Internet) are less likely to adopt the kind of cognitive strate- 
gy needed to reach a solution when the solution is readily available.

\subsection{Multitasking}

In a recent survey, $50 \%$ of adolescents reported that they often or sometimes use social media while doing homework (Common Sense Media, 2015). Although many of these teens did not feel that this kind of multitasking affected their ability to do their homework (Common Sense Media, 2015), doing two tasks simultaneously has been shown to result in performance decrements. While an early study found that selfreported heavy media multitaskers were worse at switching between two tasks than their lighter media multitasking counterparts (Ophir, Nass, \& Wagner, 2009), the opposite was found for a more recent study (Alzahabi \& Becker, 2013). The more recent study by Alzahabi and Becker included a direct replication of the Ophir et al. (2009) study as well as an original study with a number of methodological differences, both of which yielded the same finding that heavy media multitaskers were better at switching between tasks than light media multitaskers. These two studies investigated these multitasking effects in samples of undergraduate students, and it could be that all individuals in the more recent sample had more experience with media multitasking than the individuals in the Ophir et al. (2009) sample, given the rapid changes in media use that have occurred in the intervening period.

While not a direct study of how online behaviors influence cognitive processes, a recent study investigated specifically how one aspect of the online environment-multitasking during social interactions-could impact performance in both adolescents and adults (Mills, Dumontheil, Speekenbrink, \& Blakemore, 2015). This study found that adolescents are more sensitive to additional cognitive load requirements than are adults in both social and non-social multitasking situations (Mills et al., 2015). However, both adolescents and adults showed performance decrements when multitasking during social interactions that required perspective taking (Mills et al., 2015). These results suggest that the natural pace of social interactions (which can evolve on a millisecond basis) could be disrupted when adolescents or adults are simultaneously keeping track of extraneous information-as is often done when using digital devices in social situations.

\subsection{Processing Social Cues}

It is difficult to determine what might be lost when individuals interact primarily through digital means, and experimental studies that test both offline and online forms of communication are rare. One study examined how different forms of communication (face-to-face, video chat, audio chat, and instant messaging) impact feelings of bonding and affiliation in a group of college students (Sherman, Michikyan, \& Greenfeld, 2013). By coding the amount of interpersonal cues shared between two friends in these four types of interaction, these researchers were able to parse apart how digital communication could impact relationships. They found that interpersonal cues were lower in communications through digital media and that this decline was associated with decreased feelings of bonding and nonverbal affiliation cues (Sherman et al., 2013). However, the study also found that it was still possible to elicit feelings of bonding through the use of digital interpersonal cues (e.g., emoticons or typed laughter) in text-based communication, and that video chat elicited similar levels of bonding as face-to-face interaction (Sherman et al., 2013).

\subsection{Social Competence}

Adolescence is a time in which we hone our social navigation skills (social competence), which arguably involves a number of social cognitive processes as well as cognitive control. One of the most common online activities for adolescents is communicating with others, primarily individuals known offline (Reich et al., 2012). Use of social networking sites is associated with greater feelings of peer affiliation (Spies Shapiro \& Margolin, 2014), and adolescents who use social networking sites report less peer-related loneliness than non-users (Teppers, Luyckx, Klimstra, \& Goossens, 2014), suggesting that adolescents who use social networking sites are developing the necessary social skills to have healthy peer relationships. Indeed, older adolescents who used social networking sites more than 2 hours a day reported higher social competence than older adolescents who used these sites less (Tsitsika et al., 2014).

However, when an individual's social cognitive skills are lacking, using social network sites to compensate might not facilitate the development of healthy peer relations. Two recent studies suggest that the motivations for using social networking sites influence peer relationships, and the same motivations can lead to different outcomes for adolescents and young adults. In a longitudinal study of adolescents, use of social networking sites to compensate for weak social cognitive skills was associated with increased peer-related loneliness, but using social networking sites to form new relationships was associated with decreased peer-related loneliness (Teppers et al., 2014). In contrast, a study of American undergraduate students suggests that use of social networking sites has the potential to facilitate the transition from secondary school to college. Students who reported greater attempts to form new relationships through social networking sites were less socially adjusted and reported more loneliness than their peers who used social networking sites to maintain already existing relationships (Yang \& Brown, 
2013). However, most students in this study reported using social networking sites to maintain relationships with pre-collegiate friends rather than to establish new relationships (Yang \& Brown, 2013). But no matter the motivation, the more students engaged in online interactions through social networking sites the better their social adjustment and less their sense of loneliness (Yang \& Brown, 2013).

\subsection{Social Evaluation}

One concern about being online 'almost constantly' is how it could make an individual feel as though online peers are constantly evaluating her or him. This could be particularly problematic for adolescents, who are already highly sensitive to social evaluation and exclusion (Somerville, 2013). Therefore, what we know about how adolescents respond to social evaluation is likely relevant to understanding how being nearly always connected to one's peers could affect cognition. There have now been a few developmental cognitive studies that have explored how this feature of the online environment could affect cognitive processes in adolescents.

When a group of adolescents believed they were being watched by a peer in a laboratory setting, they reported greater embarrassment than children, and showed greater physiological levels of arousal than children or adults (Somerville et al., 2013). When a group of older adolescents (aged 15 to 18 years) were actually watched by a physically present peer while performing a difficult cognitive task, they performed worse than if they were watched by an adult experimenter or when performing the task alone (Wolf, Bazargani, Kilford, Dumontheil, \& Blakemore, 2015). Younger adolescents (aged 11 to 14 years) performed worse on even simple cognitive tasks when being watched by a peer relative to an adult experimenter or when alone (Wolf et al., 2015). These two experiments suggest that constant social evaluation by peers could increase the baseline level of arousal, or alertness, of adolescents, as well as decrease ability to perform tasks as well as they might when not in social evaluative contexts.

Another study measured how adolescents reacted to peer acceptance or rejection in a task that simulated a live Internet chat room (Silk et al., 2012). Although participants in this study were more likely to direct their attention toward acceptance feedback and away from rejection feedback, they showed more emotional and cognitive reactivity to rejection feedback (as measured by pupil dilation) (Silk et al., 2012). Further, the participants that reacted most strongly to the rejection feedback during the task were more likely to report feelings of social disconnectedness in daily life. These findings suggest that online interactions have real-world consequences for the cognitive processes of adolescents, although it is unclear if this relationship is limited to online peer interactions.

\section{Discussion}

There have now been several experimental studies with cleverly designed tasks relevant to our understanding of how Internet use could impact cognition. The current review identified several experimental studies that examined how online structures or online behaviors affect cognitive processes, as well as empirical studies that assessed the effects of actual Internet use on cognitive processes. These two kinds of studies provide converging evidence to address the question of how Internet use affects the cognitive development of adolescents and emerging adults.

For the most part, access to the Internet equals access to the collective history of human knowledge, including both reliable and unreliable sources of information. The findings outlined in the present review suggest that our ways of dealing with information are different in structures that mimic access to the Internet. At least for undergraduates, having access to the collective memory bank of the Internet could decrease memory for specific pieces of information in exchange for an increased memory for how to obtain a specific piece of information (Sparrow et al., 2011). Practically, this kind of change in cognitive strategy might prove to be more efficient in a society where access to the Internet is stable. Furthermore, undergraduates appear to be weighting the information they obtain from the Internet according to the reliability of the source (Fenn et al., 2014), as well as considering the reliability of their own memory differently when access to correct information is available through the Internet (Ferguson et al., 2015).

Another feature of Internet use is the ability to engage in several tasks at once, including switching between offline and online tasks, as several studies of adolescents and emerging adults report doing (Common Sense Media, 2015; Moreno et al., 2012; Rosen, Mark Carrier, \& Cheever, 2013). While there are discrepant findings as to how levels of real-life media multitasking affect the task-switching abilities of undergraduate students (Alzahabi \& Becker, 2013; Ophir et al., 2009), one study found that both adolescents and adults are impaired in social interactions that require perspective taking in cognitively demanding multitasking situations (Mills et al., 2015).

Learning how to navigate our complex social world is a major developmental task of adolescence. Changes that occur during adolescence-including increased cognitive abilities, social sensitivity, and striving for independence-naturally facilitate the successful completion of this task (Blakemore \& Mills, 2014). Given the prevalence of Internet use, a common concern of parents and policy makers is how online social interactions could impact adolescent social cognitive development. Early studies have reported positive social outcomes for adolescents who use the Internet to communicate with individuals known offline (Valken- 
burg \& Peter, 2009), and recent studies looking at social networking site use report largely the same (Spies Shapiro \& Margolin, 2014). Indeed, communicating through digital means is still able to elicit feelings of bonding through the use of text-based cues like typed laughter (Sherman et al., 2013), and perhaps increased use social networking sites allows for more adept digital communication of social nuances, leading to increased overall social competence (Tsitsika et al., 2014; Yang \& Brown, 2013). However, individual differences in baseline social cognitive skills might mediate the social benefits of Internet communication (Teppers et al., 2014). Finally, online evaluation from peers is likely to affect cognitive processes, although it is unclear how specific these effects are to the online environment (Silk et al., 2012; Somerville et al., 2013; Wolf et al., 2015).

\section{Limitations and Future Directions}

While experimental studies can give us insights that are lacking in survey-based studies, we cannot be certain that their findings are relevant to Internet use unless the effects are measured in relation to online activities. Therefore, more studies that incorporate both experimental manipulations of online behaviors or online structures should also include survey-based measures of actual internet use, as has been done in the multitasking literature (Alzahabi \& Becker, 2013; Ophir et al., 2009). In addition, laboratory measures of Internet use would be more ecologically valid if they mimicked actual online behaviors like using social media platforms (e.g., Fenn et al., 2014). Furthermore, the majority of experimental studies investigating possible links between Internet use and cognition have been conducted on adults or undergraduate college students. In order to understand how near-constant access to the Internet could affect memory or the cognitive strategies of adolescents, future studies should include samples of younger participants. Finally, some concerns about Internet use have yet to be addressed in survey or experimental research. For example, we do not know how having near-constant access to the Internet, especially through mobile devices, might displace time left alone to one's own thoughts (e.g., on the bus or in a queue). As the research on how mind wandering impacts cognitive processes accumulates (Smallwood \& Schooler, 2015), investigations of the opposite-having a lack of personal downtime-are similarly needed.

In addition to new empirical work, new reviews will continue to be necessary in order to integrate swiftly accumulating empirical evidence, and the effects of the latest usage of evolving digital technologies. For example, early reviews examining the relationship between Internet use and social development focused on evidence from investigations of chat room or instant messaging activities (Subrahmanyam \& Greenfield, 2008; Valkenburg \& Peter, 2009), whereas more recent re- views have focused on evidence from investigations of social media use (Spies Shapiro \& Margolin, 2014; Wu, Outley, Matarrita-Cascante, \& Murphrey, 2015). While both older and newer reviews on this topic suggest that online behaviors involving offline friends have the capability of strengthening relationships during adolescence, newer reviews were able to integrate more evidence to suggest baseline social skills increase the chance for adolescents to reap the benefits of social media use (Spies Shapiro \& Margolin, 2014). Given the lack of older reviews on the topic of how Internet use affects cognitive development, the results of the current review could not be integrated into previous syntheses of the literature.

\section{Conclusion}

The questions addressed in the present review stem from concerns expressed by adults that behaviors surrounding new technologies, such as widespread access and usage of the Internet, could alter the typical course of cognitive development. The findings of this review suggest that cognitive changes are likely taking place, but that these changes are not necessarily impeding adolescents' or emerging adults' ability to successfully navigate our highly-connected world. Indeed, adaptation to these new technologies appears to be associated with greater integration into peer groups and even increased cognitive abilities such as faster taskswitching. While these results could surprise the generation of adults that have expressed fears about the effects of new digital technologies, they may not surprise the generation of adolescents or adults that grew up with them. In fact, in societies where Internet use is ubiquitous, access to the Internet can be viewed as essential to completing major developmental tasks in adolescence. When interviewed, Italian adolescents reported feeling as though the Internet facilitated the tasks of forming one's identity, establishing personal autonomy, and strengthening peer relationships (Borca, Bina, Keller, Gilbert, \& Begotti, 2015). Another study that interviewed American 13-14 year olds obtained similar reports, as these adolescents largely expressed positive perceptions of the effects of technology on their cognitive and social development (Fitton et al., 2013). Perhaps any changes in cognition that accompany Internet use are not a cause for concern, but rather a positive adaption to a changing environment.

Overall, the findings of the present review cannot give a definitive answer to the question of how Internet use could affect the cognitive development of adolescents. There is simply not enough empirical evidence accumulated to make a case that Internet use is altering the cognitive abilities of adolescents who have grown up with near-constant access to the Internet. There is evidence for changes in cognitive strategies in experimental paradigms that mimic online environments, but most of these studies have investigated sam- 
ples of undergraduate students. Future studies that integrate experimental manipulations of online behaviors or online structures with measures of actual Internet use will be necessary, as well as reviews of the growing literature on cognitive processes and Internet use.

\section{Acknowledgments}

The author thanks Joseph Mitchell for his comments on previous versions of the manuscript and Celilo Mitchell for initial inspiration.

\section{Conflict of Interests}

The author declares no conflict of interests.

\section{References}

Alzahabi, R., \& Becker, M. W. (2013). The association between media multitasking, task-switching, and dualtask performance. Journal of Experimental Psychology: Human Perception and Performance, 39(5), 14851495. doi:10.1037/a0031208

Barrense-Dias, Y., Berchtold, A., Akre, C., \& Surís, J.-C. (2015). The relation between internet use and overweight among adolescents: A longitudinal study in Switzerland. International Journal of Obesity. doi:10. 1038/ijo.2015.146

Blakemore, S.-J., \& Mills, K. L. (2014). Is adolescence a sensitive period for sociocultural processing? Annual Review of Psychology, 65(1), 187-207. doi:10.1146/ annurev-psych-010213-115202

Borca, G., Bina, M., Keller, P., Gilbert, L., \& Begotti, T. (2015). Internet use and developmental tasks: Adolescents' point of view. Computers in Human Behavior, 52, 49-58. doi:10.1016/j.chb.2015.05.029

Common Sense Media. (2015). The Common Sense census: Media use by tweens and teens. Retrieved from https://www.commonsensemedia.org/research/thecommon-sense-census-media-use-by-tweens-andteens

Durkee, T., Kaess, M., Carli, V., Parzer, P., Wasserman, C., Floderus, B., ... Wasserman, D. (2012). Prevalence of pathological internet use among adolescents in Europe: Demographic and social factors. Addiction, 107(12), 2210-2222. doi:10.1111/j.1360-0443.2012. 03946.x

Fenn, K. M., Griffin, N. R., Uitvlugt, M. G., \& Ravizza, S. M. (2014). The effect of Twitter exposure on false memory formation. Psychonomic Bulletin \& Review, 21(6), 1551-1556. doi:10.3758/s13423-014-0639-9

Ferguson, A. M., McLean, D., \& Risko, E. F. (2015). Answers at your fingertips: Access to the Internet influences willingness to answer questions. Consciousness and Cognition, 37, 91-102. doi:10.1016/j.concog. 2015.08.008

Fisher, M., Goddu, M. K., \& Keil, F. C. (2015). Searching for explanations: How the Internet inflates estimates of internal knowledge. Journal of Experimental Psychology, 144(3), 674-687. doi:10.1037/xge0000070

Fitton, V. A., Ahmedani, B. K., Harold, R. D., \& Shifflet, E. D. (2013). The role of technology on young adolescent development: Implications for policy, research and practice. Child and Adolescent Social Work Journal, 30(5), 399-413. doi:10.1007/s10560-013-0296-2

Gámez-Guadix, M., Calvete, E., Orue, I., \& Las Hayas, C. (2015). Problematic Internet use and problematic alcohol use from the cognitive-behavioral model: A longitudinal study among adolescents. Addictive Behaviors, 40, 109-114. doi:10.1016/j.addbeh.2014.09.009

George, M. J., \& Odgers, C. L. (2015). Seven fears and the science of how mobile technologies may be influencing adolescents in the digital age. Perspectives on Psychological Science, 10(6), 832-851. doi:10.1177/ 1745691615596788

Lenhart, A. (2015). Teens, social media \& technology overview 2015. Pew Research Center. Retrieved from http://www.pewinternet.org/2015/04/09/teenssocial-media-technology-2015

Lenhart, A., Smith, A., Anderson, M., Duggan, M., \& Perrin, A. (2015). Teens, technology and friendships. Pew Research Center. Retrieved from http://www. pewinternet.org/2015/08/06/teens-technology-andfriendships

Luna, B., Marek, S., Larsen, B., Tervo-Clemmens, B., \& Chahal, R. (2015). An integrative model of the maturation of cognitive control. Annual Review of Neuroscience, 38(1), 151-170. doi:10.1146/annurev-neuro071714-034054

Mills, K. L. (2014). Effects of Internet use on the adolescent brain: Despite popular claims, experimental evidence remains scarce. Trends in Cognitive Sciences, 18(8), 385-387. doi:10.1016/j.tics.2014.04.011

Mills, K. L., Dumontheil, I., Speekenbrink, M., \& Blakemore, S.-J. (2015). Multitasking during social interactions in adolescence and early adulthood. Royal Society Open Science, 2(11), 150117. doi:0.1098/rsos. 150117

Moreno, M. A., Jelenchick, L., Koff, R., Eikoff, J., Diermyer, C., \& Christakis, D. A. (2012). Internet use and multitasking among older adolescents: An experience sampling approach. Computers in Human Behavior, 28(4), 1097-1102. doi:10.1016/j.chb.2012.01.016

Näsi, M., \& Koivusilta, L. (2012). Internet and everyday life: The perceived implications of internet use on memory and ability to concentrate. Cyberpsychology, Behavior, and Social Networking, 16(2), 88-93. doi:10.1089/cyber.2012.0058

Ophir, E., Nass, C., \& Wagner, A. D. (2009). Cognitive control in media multitaskers. Proceedings of the $\mathrm{Na}$ tional Academy of Sciences. doi:10.1073/pnas. 0903620106

Rahwan, I., Krasnoshtan, D., Shariff, A., \& Bonnefon, J.-F. (2014). Analytical reasoning task reveals limits of so- 
cial learning in networks. Journal of the Royal Society, Interface/the Royal Society, 11(93). doi:10.1098/ rsif.2013.1211

Reich, S. M., Subrahmanyam, K., \& Espinoza, G. (2012). Friending, IMing, and hanging out face-to-face: Overlap in adolescents' online and offline social networks. Developmental Psychology, 48(2), 356-368. doi:10. 1037/a0026980

Rosen, L. D., Mark Carrier, L., \& Cheever, N. A. (2013). Facebook and texting made me do it: Media-induced task-switching while studying. Computers in Human Behavior, 29(3), 948-958. doi:10.1016/j.chb.2012.12. 001

Sherman, L. E., Michikyan, M., \& Greenfeld, P. M. (2013). The effects of text, audio, video, and in-person communication on bonding between friends. Cyberpsychology: Journal of Psychosocial Research on Cyberspace, 7(2). Retrieved from http://www.cyber psychology.eu/view.php?cisloclanku=2013071101\&a rticle $=1$

Silk, J. S., Stroud, L. R., Siegle, G. J., Dahl, R. E., Lee, K. H., \& Nelson, E. E. (2012). Peer acceptance and rejection through the eyes of youth: Pupillary, eyetracking and ecological data from the Chatroom Interact task. Social Cognitive and Affective Neuroscience, 7(1), 93105. doi:10.1093/scan/nsr044

Smallwood, J., \& Schooler, J. W. (2015). The science of mind wandering: Empirically navigating the stream of consciousness. Annual Review of Psychology, 66, 487518. doi:10.1146/annurev-psych-010814-015331

Somerville, L. H. (2013). The teenage brain sensitivity to social evaluation. Current Directions in Psychological Science, 22(2), 121-127. doi:10.1177/09637214134 76512

Somerville, L. H., Jones, R. M., Ruberry, E. J., Dyke, J. P., Glover, G., \& Casey, B. J. (2013). The medial prefrontal cortex and the emergence of self-conscious emotion in adolescence. Psychological Science, 24(8), 1554-1562. doi:10.1177/0956797613475633

Sparrow, B., Liu, J., \& Wegner, D. M. (2011). Google effects on memory: Cognitive consequences of having information at our fingertips. Science, 333(6043), 776-778. doi:10.1126/science.1207745

Spies Shapiro, L. A., \& Margolin, G. (2014). Growing up wired: Social networking sites and adolescent psychosocial development. Clinical Child and Family Psychology Review, 17(1), 1-18. doi:10.1007/s10567013-0135-1

\section{About the Author}

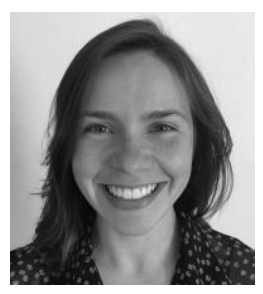

\section{Dr. Kate Mills}

Kate Mills is a postdoctoral research associate in the Developmental Social Neuroscience Lab at University of Oregon. Her research uses brain imaging methods to investigate typical developmental trajectories between childhood and adulthood, as well as behavioral experiments to investigate how we navigate the social environment in adolescence and adulthood. 